\section{JTI}

JOURNAL OF

TRAUMA AND INJURY
Received: May 7, 2020

Revised: July 20, 2020

Accepted: August 4, 2020

\section{Correspondence to}

Yang Bin Jeon, M.D., Ph.D.

Department of Traumatology, Gachon University College of Medicine, 38-13

Dokjeom-ro 3beon-gil, Namdong-gu, Incheon 21565, Korea

Tel: $+82-32-460-3010$

Fax: +82-32-460-2372

E-mail:junyb@gilhospital.com

\title{
Traumatic Tricuspid Regurgitation as a Cause of Failure to Wean from Mechanical Ventilation
}

\author{
Yang Bin Jeon, M.D., Ph.D. ${ }^{1}$, Chul Hyun Park, M.D., Ph.D. ${ }^{2}$, Dae Sung Ma, M.D. ${ }^{3}$ \\ ${ }^{1}$ Department of Traumatology, Gachon University College of Medicine, Incheon, Korea \\ ${ }^{2}$ Department of Thoracic and Cardiovascular Surgery, Gachon University College of \\ Medicine, Incheon, Korea \\ ${ }^{3}$ Department of Thoracic and Cardiovascular Surgery, Dankook University Hospital, \\ Cheonan, Korea
}

\begin{abstract}
A 55-year-old man underwent emergent sternotomy due to cardiac tamponade occurring just after an accidental fall from a 10-m height. Tricuspid valve regurgitation was found on echocardiography while he was on mechanical ventilation after the operation. The patient was weaned successfully from mechanical ventilation after tricuspid valve repair under cardiopulmonary bypass. Traumatic tricuspid valve regurgitation is a rare blunt chest injury and its symptoms occur late. Tricuspid regurgitation should be considered as a reason for failure to wean from mechanical ventilation after blunt cardiac trauma.
\end{abstract}

Keywords: Tricuspid valve regurgitation; Trauma; Cardiac tamponade

\section{INTRODUCTION}

Cardiac valve injury by trauma occurs in $9 \%$ of patients with blunt cardiac trauma according to Parmley and colleagues, and aortic valve injury is the most common type of these injuries [1]. Injury of the tricuspid valve structures after blunt chest trauma has rarely been reported [1-4]. Traumatic tricuspid valve regurgitation (TTR) is usually well tolerated [5]; however, tricuspid valve replacement is the conventional treatment in cases with delayed presentation [6]. Particularly in patients with multiple trauma, other associated injuries may obscure cardiac symptoms and signs, thereby causing delays in the diagnosis and treatment of cardiac valve injury. We experienced a noteworthy case of traumatic TR in the early phase of multiple trauma. (http://creativecommons.org/licenses/by-nc/4.0/) which permits unrestricted noncommercial use, distribution, and reproduction in any medium, provided the original work is properly cited. 


\section{CASE REPORT}

A 55-year-old man was transported by helicopter with mental changes that developed after an accidental fall from a 10-m height. Soon after arrival, his systolic blood pressure was $62 \mathrm{mmHg}$, his pulse rate was 130 beats per minute, his respiratory rate was 28 breaths per minute, his body temperature was $35.5^{\circ} \mathrm{C}$, and his neck vein was not distended. Initial arterial blood gas analysis showed the following findings: $\mathrm{pH}, 7.29 ; \mathrm{PCO}_{2}, 46 \mathrm{mmHg} ; \mathrm{PO}_{2}$, $114 \mathrm{mmHg}$; base excess, -4.5 ; lactate, $5.5 \mathrm{mmol} / \mathrm{L}$; and hemoglobin, $12.6 \mathrm{~g} / \mathrm{dL}$. We started fluid resuscitation with 2,500 mL of normal saline, two pints of packed red blood cells, and $0.5 \mathrm{mg} / \mathrm{kg} / \mathrm{min}$ of norepinephrine. We checked whole-body computed tomography (CT) 2 hours after the start of resuscitation because of uncertain Focused Assessment of Sonography for Trauma (FAST) results and normal chest X-ray findings (Fig. 1A). CT showed a small to moderate amount of pericardial effusion (Fig. 2), which we thought indicated cardiac tamponade. As soon as the diagnosis was made, we went to the operating theater and opened the chest by a median sternotomy incision. When we opened the pericardial sac, we found a small amount of blood. The right atrium (RA) was bruised and there was a $1-\mathrm{cm}$ laceration between the RA and the superior vena cava. The right pleura had a pinpoint-size opening.
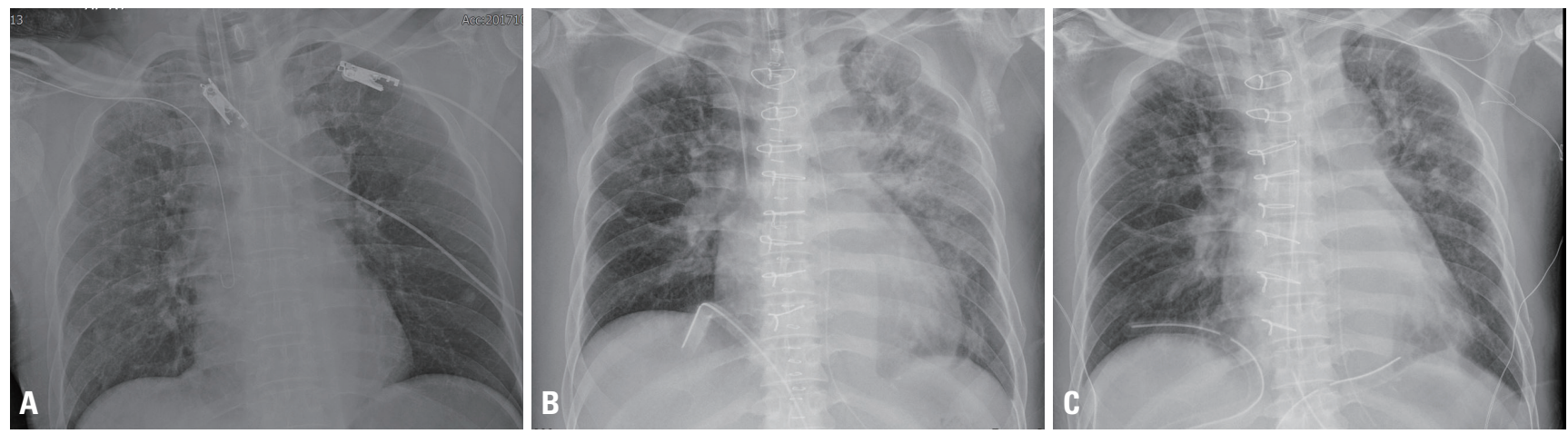

Fig. 1. Chest $X$ ray (CXR) shows a change of cardiac silhouette according to time sequence. $(A)$ is the $C X R$ at the time of arrival at the trauma bay. (B) shows cardiomegaly and lung filtration after 5 days of emergency operation. (C) is the CXR on the first day after correction of tricuspid regurgitation.
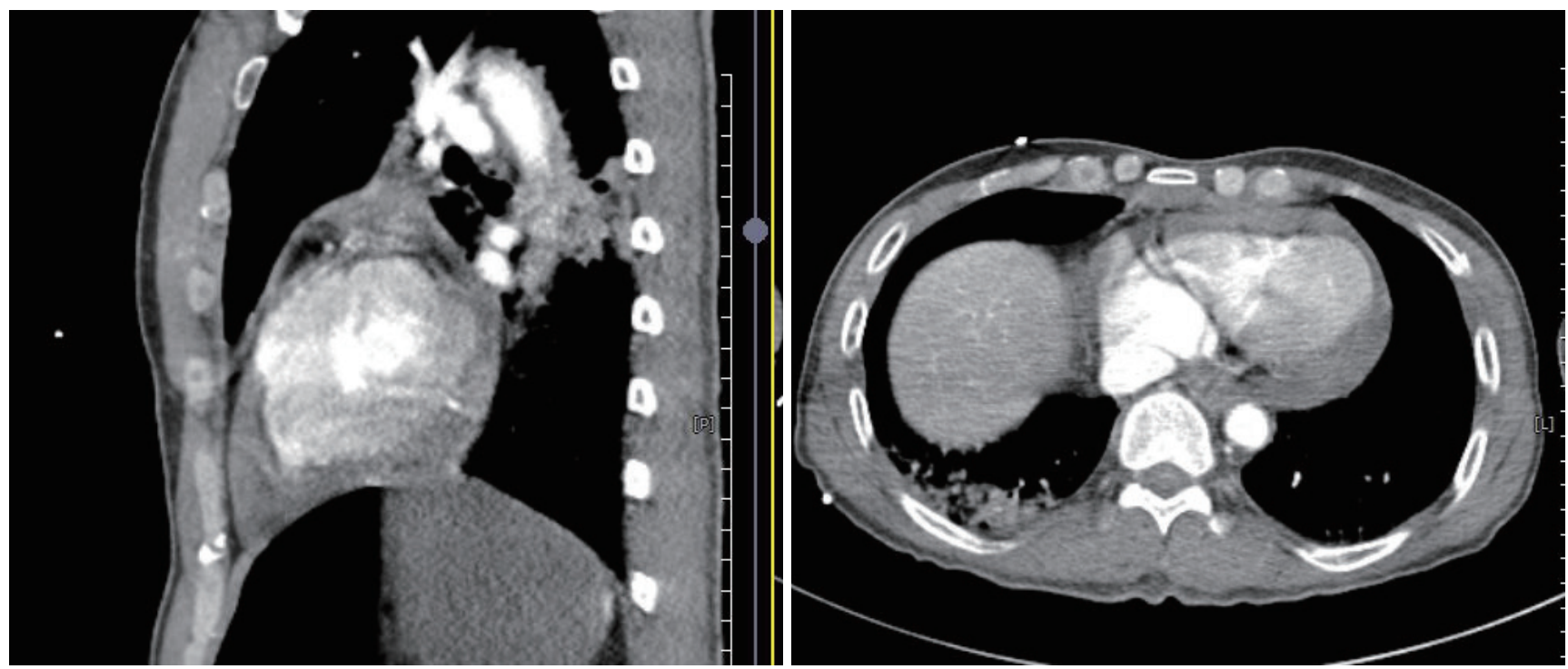

Fig. 2. Chest computed tomography shows pericardial effusion (hemopericardium) at trauma bay. 


\section{JTI}

We closed the laceration with a figure-of- 8 suture, extended the right pleural opening, and inserted a chest tube. After sternotomy, the patient was sedated and placed on mechanical ventilation because of hypo-oxygenation and difficulty in weaning from the ventilator. On the 5 th postoperative day, the patient showed marked cardiomegaly (Fig. 1B) and we conducted cardiac echocardiography (Fig. 3). The echocardiogram showed severe TR with anterior leaflet flail movement, enlargement of the RA and the right ventricle, and pulmonary hypertension with a mean pulmonary artery pressure of $43 \mathrm{mmHg}$. We planned open heart surgery for severe TR. The second operation was performed under cardiopulmonary bypass. The heart was arrested with cardioplegic solution and the RA was explored. The anterior papillary muscle (APM) and connecting chordae were cut from the ventricular wall and a remnant patent foramen ovale (PFO) was found (Fig. 4). The rupture was repaired by reimplantation of APM to the ventricular septum near the tear site with two pledgeted 5-0 Prolene sutures. Additionally, the annulus was reduced by a modified DeVega annuloplasty, and the PFO was closed. The patient was extubated on the first postoperative day (Fig. 1C). He underwent four operations for his combined injuries and was discharged uneventfully.

\section{DISCUSSION}

Isolated TTR has been sparsely reported and there have been no large-scale studies yet. However, in recent years, early evaluations of cardiac injury have become more common in blunt chest trauma patients, as reported in several case reports, case series, and a literature review [1-6]. Some of these injuries are diagnosed months or years after the initial injury when a new murmur is heard [1,4-6], while others are diagnosed acutely because of hemodynamic disability $[2,3]$.

The purported mechanism of injury is compression of the heart during late diastole or isovolemic systole [7]. At this time, the cardiac chambers are full and the valves are

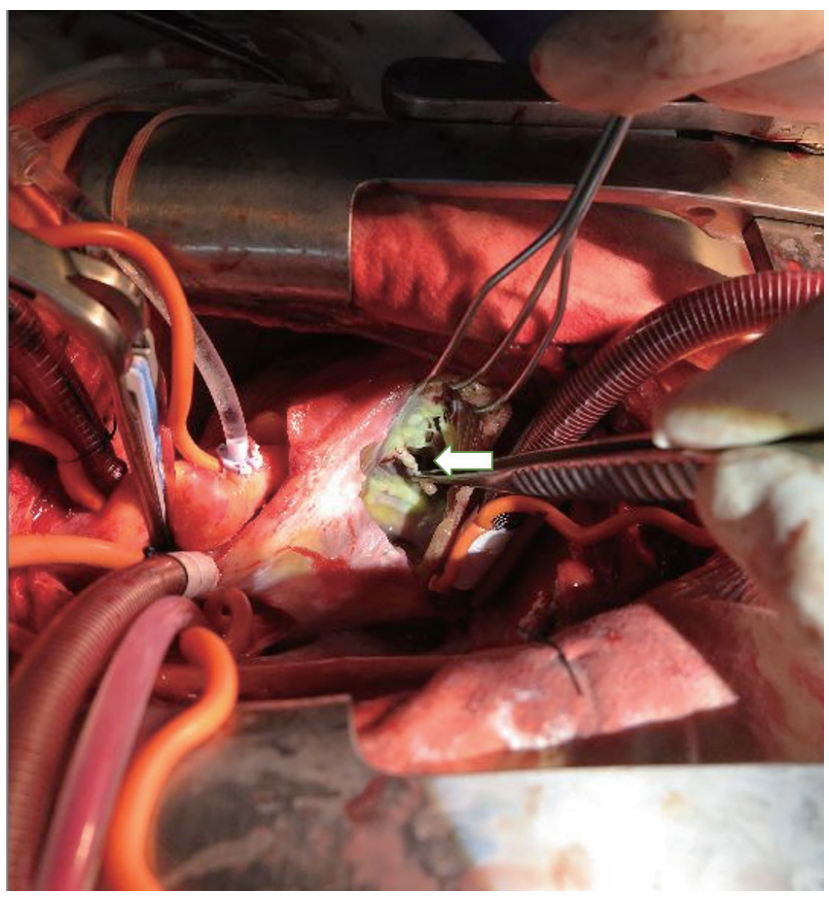

Fig. 4. Right atrium is opened during cardioplegic arrest of heart. Arrow is the ruptured anterior papillary muscle of tricuspid valve.
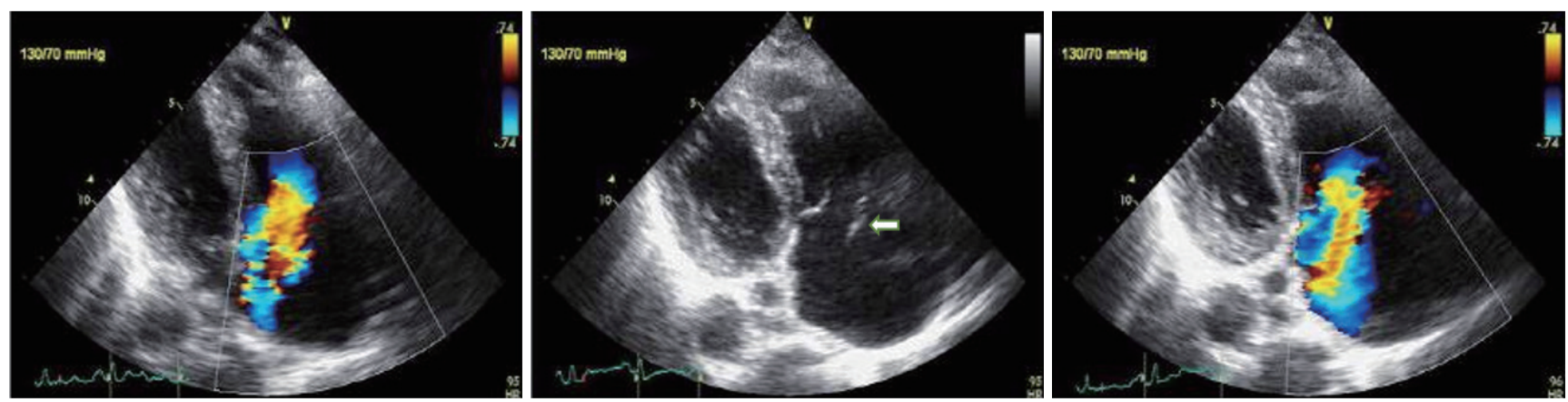

Fig. 3. Echocardiography shows tricuspid valve regurgitation on 5th days after first operation. Color Doppler image shows tricuspid valve regurgitation and the arrow is the prolapsed anterior leaflet of tricuspid valve. 
closing or closed. Acute, significant thoracic compression that occurs during a fall, a traffic accident, or blunt force impact transmits pressure, and is likely to lead to severe atrioventricular valve prolapse and rupture. Damage or disruption at the chordal or papillary muscle level is typical [8]. In the review of 74 surgical cases by Maisano et al. [6], chordal rupture was the most frequent cause of traumatic tricuspid regurgitation, occurring in 41 cases (55.4\%); other causes were papillary muscle rupture in 20 cases (27\%) and leaflet rupture in 11 cases (14.8\%).

Clinical manifestations are correlated with the severity of the lesions and vary from asymptomatic cases to congestive heart failure [9]. In some cases, papillary muscle rupture as a structural anomaly does not cause early symptoms, and may only be detectable as an electrocardiographic abnormality or radiologic cardiomegaly that regresses spontaneously within a few years [10]. However, in other cases with severe damage, it can produce hemodynamic instability and clinical deterioration [2,3]. Clinically, in patients with a history of severe blunt chest trauma who present with palpitation, dyspnea, and complete or incomplete right bundle branch blockade on electrocardiography, TTR should be strongly suspected. However, it may be missed if the patient is unconscious or has additional combined injuries. Our patient showed severe hypovolemic shock, confusion, and FAST presentation of cardiac tamponade on arrival. Therefore, we performed emergent sternotomy without echocardiography.

If TTR is detected, accidentally or deliberately, and the decision is made to operate, a further decision should be made about when to operate. Symptomatic heart failure is usually a strong indication for surgery, and an early operation allows preservation of myocardial reserve by preventing secondary myocardial changes [6]. Nonetheless, the timing of the operation is controversial, and many surgeons make an individualized decision for each patient; however, we personally insist on operating as soon as possible before congestive heart failure progresses.

We thought that this patient exhibited competition with the ventilator and did not adapt to mechanical ventilation because of other combined injuries after the emergent operation. We placed the patient under deep sedation, which is the first reason why we missed the diagnosis. For 5 days, we checked chest X-rays and controlled the ven- tilator for weaning but did not listening to heart sound carefully. This was the second mistake we made. On the 5th postoperative day, we found noticeable cardiomegaly and checked the patient's heart sounds and echocardiography. Therefore, we recommend auscultation and echocardiography for patients who have sustained severe blunt chest trauma to detect tricuspid insufficiency or myocardial contusion as early as possible.

The surgical treatment of TTR includes valve repair or replacement, and it depends on the time of diagnosis. In the acute phase, most surgeons prefer valve repair because the injured chordae tendineae or papillary muscle are fresh for suturing or reimplantation. However, in the chronic phase, papillary muscles, chordae tendineae, and the involved leaflet(s) are frequently found in a contracted and atrophic state, for which reason surgeons may prefer valve replacement with a mechanical artificial valve or a tissue bioprosthetic valve. We recommend a careful observation for a patient with severe blunt chest trauma because traumatic tricuspid valve regurgitation may be a reason of failure to wean from mechanical ventilation in intensive care unit.

\section{REFERENCES}

1. Ma WG, Luo GH, Sun HS, Xu JP, Hu SS, Zhu XD. Surgical treatment of traumatic tricuspid insufficiency: experience in 13 cases. Ann Thorac Surg 2010;90:1934-8.

2. Enomoto Y, Sudo Y, Sueta T. Traumatic tricuspid insufficiency requiring valve repair in an acute setting. Hellenic J Cardiol 2015;56:516-9.

3. Stoica B, Paun S, Tanase I, Negoi I, Runcanu A, Beuran M. Traumatic tricuspid valve rupture after blunt chest trauma a case report and review of the literature. Chirurgia (Bucur) 2015;110:467-70.

4. Croxson MS, O’Brien KP, Lowe JB. Traumatic tricuspid regurgitation. Long-term survival. Br Heart J 1971;33:750-5.

5. Fujiwara K, Hisaoka T, Komai H, Nishimura Y, Yamamoto S, Okamura Y. Successful repair of traumatic tricuspid valve regurgitation. Jpn J Thorac Cardiovasc Surg 2005;53:259-62.

6. Maisano F, Lorusso R, Sandrelli L, Torracca L, Coletti G, La Canna G, et al. Valve repair for traumatic tricuspid regurgitation. Eur J Cardiothorac Surg 1996;10:867-73. 
7. Cuadros CL, Hutchinson JE 3rd, Mogtader AH. Laceration of a mitral papillary muscle and the aortic root as a result of blunt trauma to the chest. Case report and review of the literature. J Thorac Cardiovasc Surg 1984;88:134-40.

8. Banning AP, Durrani A, Pillai R. Rupture of the atrial septum and tricuspid valve after blunt chest trauma. Ann Thorac Surg 1997;64:240-2.
9. Krasna MJ, Flancbaum L. Blunt cardiac trauma: clinical manifestations and management. Semin Thorac Cardiovasc Surg 1992;4:195-202.

10. Toggweiler S, Turina J, Jenni R, Tanner FC. Spontaneous regression of severe traumatic tricuspid valve regurgitation. Eur Heart J 2010;31:560. 